Berkala Ilmu Perpustakaan dan Informasi, Vol. 17, No. 2, Desember 2021, Hal. 154-167 https://doi.org/10.22146/bip.v17i1.1789

ISSN 1693-7740 (Print), ISSN 2477-0361 (Online)

Tersedia online di https://journal.ugm.ac.id/v3/BIP

\title{
Teamwork skills pada peer consultant writing center dan mahasiswa pengguna jasanya
}

\author{
Gennesia Vebriana ${ }^{1}$, Elisabeth Rukmini ${ }^{2}$ \\ ${ }^{1}$ Medical Education Unit, Fakultas Kedokteran dan Ilmu Kesehatan, Universitas Katolik Indonesia Atma Jaya \\ ${ }^{2}$ Program Studi Teknik Sipil \& Center for Urban Studies (CUS) Universitas Pembangunan Jaya \\ ${ }^{1}$ Jl. Pluit Selatan Raya 2, Jakarta Utara 14440 \\ ${ }^{2} J 1$. Cendrawasih Raya Blok B7/P, Bintaro Jaya, Sawah Baru, Ciputat, Tangerang Selatan 15413 \\ e-mail: elisabeth.rukmini@upj.ac.id
}

Naskah diterima: 3 Mei 2021, direvisi: 9 Agustus 2021, disetujui: 25 Agustus 2021

\begin{abstract}
ABSTRAK
Pendahuluan. Writing center sebagai layanan konsultasi ilmiah dapat membantu mahasiswa untuk menyelesaikan penulisan ilmiah serta meningkatkan keterampilan non-teknis. Penelitian ini bertujuan untuk mengetahui pengaruh writing center pada kemampuan kerja sama mahasiswa.

Metode penelitian. Penelitian merupakan studi deskriptif dan eksploratif secara potong lintang. Metode kuantitatif menggunakan pengukuran Teamwork Skills Questionnaire pada tiga kondisi pengambilan dan data kualitatif diperoleh dari wawancara mendalam. Kedua jenis data didapatkan dari partisipan peer-consultant (PC) dan pengguna jasa writing center.

Data analisis. Analisis data kuanitatif menggunakan one-way ANOVA repeated measures dan analisis data kualitatif menggunakan metode analisis konten.

Hasil dan Pembahasan. Dari analisis data didapatkan nilai $p 0,857$ pada PC dan 0,044 pada pengguna. Hal ini menunjukkan peningkatan yang signifikan pada kemampuan kerja sama pengguna. Walaupun hasil kuantitatif PC tidak bermakna, pada hasil kualitatif, PC menjelaskan bahwa writing center dapat melatih kerja sama secara tidak langsung seperti kemampuan komunikasi, adapatasi, memimpin dan kolaborasi.

Kesimpulan dan Saran. Kerja sama yang dimiliki mahasiswa sebelum dan sesudah program writing center dikategorikan tinggi. writing center memiliki pengaruh terhadap kemampuan kerja sama PC dan penggunanya. writing center perlu dipertimbangkan untuk diterapkan sebagai layanan perguruan tinggi.
\end{abstract}

Kata kunci: kerja sama; writing center; tutor sebaya

\section{ABSTRACT}

Introduction. Writing centers help students to complete their scientific writing and improve their non-technical skills. This study aims to describe the impacts of writing center existance on students'teamwork abilities.

Data Collection Methods. This paper contains cross-sectional descriptive and explorative study. The quantitative method measured students' teamwork with Teamwork Skills Questionnaire within the three particular situations. The qualitative method was conducted by in-depth interviews. Participants consisted of peer-consultants (PCs) and users of the writing center.

Data Analysis. Quantitative data analysis used one-way ANOVA repeated measure, and qualitative data analysis used the content analysis.

Results and Discussion. We found that the PCs p-value is 0.857 and 0.044 for the user. Results showed a significant increase in the user's teamwork ability. Although the PCs from quantitative results were not significant, the PCs qualitative analysis explained that the writing center could train teamwork indirectly through communication skills, adaptation, leadership, and collaboration. 
Conclusion. The teamwork skills that students have before and after the writing center program was categorized as high. The writing center had a subtle influence on the teamwork ability of the PCs and its users. We suggest that the university elaborates the writing center as one of the students'valuable services.

Keywords: teamwork; writing center; peer tutor

\section{A. PENDAHULUAN}

Pada jaman serba canggih belakangan ini, mahasiswa lebih suka menggunakan surat elektronik dan pesan singkat pada teknologi dibandingkan melakukan penulisan. Hal ini mengakibatkan keterampilan menulis pada mahasiswa menjadi lebih rendah, termasuk pada bagian penelitian ilmiah (Simkin, 2012). Meskipun demikian, publikasi ilmiah saat ini menjadi lebih besar karena adanya publikasi elektronik (Kemenristekdikti, 2017).

Bukti menunjukkan Indonesia berada di tingkat keempat pada publikasi 572 jurnal dan hanya 32 jurnal yang terindeks Scopus hingga tahun 2017. Tingkat publikasi ilmiah di Indonesia tidak lebih tinggi dari negara-negara Asia lain seperti Malaysia dan Thailand (Kemenristekdikti, 2017). Rendahnya kemampuan penulisan ilmiah pada mahasiswa menjadi salah satu penyebab rendahnya publikasi di Indonesia. SINTA Kementrian Riset dan Teknologi menyatakan jumlah publikasi ilmiah yang ada di Indonesia meningkat semenjak 2005 tetapi kembali mengalami penurunan semenjak 2020 meskipun publikasi ilmiah saat ini menjadi lebih besar karena adanya publikasi elektronik (SINTA, 2021). Oleh karena itu, dukungan untuk mendorong mahasiswa menulis perlu diupayakan segenap pihak di perguruan tinggi. Dalam hal ini, penyediaan layanan dukungan penulisan adalah salah satu bentuk bantuan tersebut.

Terkait penyediaan layanan, writing center merupakan layanan dukungan universitas bagi warga kampus terutama mahasiswa. Writing center merupakan bagian dari layanan dukungan universitas di negara-negara yang telah maju. Writing center menyediakan tutor (sering disebut peer-cosultant, PC) dalam layanannya untuk membantu penulis, khususnya dalam penulisan ilmiah. PC adalah tutor sebaya yang sudah terlatih dan dipersiapkan oleh manajemen writing center untuk memberikan layanan pendampingan dalam penulisan ilmiah. Dalam hal ini, writing center menjadi ruang bagi penulis agar dapat berpikir lebih kritis mengenai kompleksitas ide penulisan sehingga dapat mendukung produktivitas penulisan mahasiswa (Bielinska, 2015). PC dalam writing center bertugas memberikan umpan balik bagi penulis (Fry et al., 2019, Rohan et al., 2020). Writing center menjadi salah satu pendekatan yang dapat membantu peningkatan kemampuan menulis ilmiah dan dapat membentuk lingkungan yang kolaboratif (Kemenristekdikti, 2017). Lingkungan yang kolaboratif umumnya membuat sebuah tim dapat bekerja sama dengan baik, khususnya dalam pelaksanaan dan penulisan ilmiah (Fry et al., 2019).

Dalam kerangka penyediaan layanan dukungan bagi mahasiswa, program writing center merupakan pilot project yang pernah dilakukan oleh Universitas Katolik Indonesia Atma Jaya (UAJ) untuk membantu penulisan tugas akhir mahasiswa. Program ini dinilai secara signifikan dapat meningkatkan minat terhadap penulisan ilmiah dan kegiatan akademis lainnya baik kemampuan berpikir kritis hingga pengembangan kreativitas penulisan. Atma Jaya Writing Center (AJWC) dinilai dapat mengembangkan kepribadian seperti meningkatkan keterampilan sosial hingga rasa tanggung jawab selain mengembangkan bidang akademis dan penulisan ilmiah (Nainggolan et al., 2013). Walaupun demikian, selama dijalankan program writing center, belum terdapat penelitian mengenai pengaruh writing center terhadap soft skills mahasiswa UAJ khususnya kemampuan kolaborasi dan kerja sama.

Oleh karena itu penelitian ini bertujuan untuk mengetahui dampak writing terhadap soft skills PC dan pengguna jasanya. Soft skills yang hendak diamati adalah kemampuan kerja sama 
PC maupun pengguna jasanya di writing center yang dijalankan oleh perpustakaan UAJ. Kemampuan kerja sama juga dinilai berdasarkan beberapa komponen yang terdapat didalamnya.

\section{B. TINJAUAN PUSTAKA}

Writing center adalah sebuah layanan konsultasi ilmiah yang menyediakan kondisi pembelajaran bagi mahasiswa untuk mendukung penulisan. Dalam penyediaan writing center, keberadaan tutor akan membantu penulis, khususnya penulisan ilmiah. Writing center juga dapat diartikan sebagai tempat yang bisa menyediakan kondisi yang membuat penulis bisa mendapatkan umpan balik yang dalam dan personal mengenai penulisannya oleh tutor (Fry et al. 2019 \& Bielinska, 2015).

Writing center yang dijalankan tidak hanya dilakukan secara tatap muka, khususnya di dunia yang lebih modern ini (McGurr, 2020). Writing center secara dalam jaringan (daring) sudah dapat dilaksanakan. Writing center dapat secara daring dijalankan dengan efektif apabila komunikasi konsultan dan pengguna berjalan dengan lancar dan mengerti satu sama lain. Walaupun demikian, gabungan antara sesi konsultasi secara daring dan tatap muka ditemukan lebih efektif. Sesi konsultasi secara daring dapat membuat tutor merasa lebih mudah untuk memberikan umpan balik sedangkan sesi konsultasi secara tatap muka membuat konsultan dan pengguna memiliki persepsi yang sama dari penulisan dan membuat hubungan interpersonal yang lebih baik. (Nainggolan et al, 2013)

Universitas di negara-negara maju menyediakan writing center sebagai standar layanan bagi penulisan mahasiswa, khususnya penulisan ilmiah. Keberadaan writing center tidak selalu hanya di kampus utama dari suatu universitas. Writing center bisa terdapat pada kampus utama, perpustakaan bersama, hingga di setiap gedung fakultas, terlebih pada fakultas rumpun kesehatan seperti kedokteran dan farmasi (McGurr, 2020).
Kesadaran yang muncul untuk meningkatkan kompetensi menulis bagi para pelajar serta hambatan yang banyak ditemukan dalam proses penulisan ilmiah membuat writing center sebagai pilihan yang sangat unggul (Prayag, 2019). Writing center membantu menyadarkan mahasiswa jurusan ilmu sains bahwa membuat karya tulis imiah adalah hal yang wajib dilakukan di bidangnya. Kemampuan menemukan hal baru serta evaluasi dari fakta hasil penemuan dapat dikomunikasikan dan disampaikan dalam tulisan yang baik (Dansereau, 2020). Penulisan ilmiah juga merupakan cara yang penting untuk menghubungkan bidang ilmiah dalam bentuk ide, kegiatan penelitan serta hasil temuan baru ke masyarakat luar (Prayag, 2019). Kompetensi menulis dianggap penting untuk kerja antarprofesi dan antardisiplin. Kemampuan menulis yang efektif dan baik merupakan landasan untuk dapat melakukan praktik berbasis bukti (evidence-based practice) dan kemampuan memimpin (Rohan et al., 2020). Writing center juga digunakan sebagai sarana untuk meningkatkan kepercayaan diri dan selfefficacy mahasiswa melalui kemampuan menulis ilmiah (Fry et al., 2019).

Dampak positif adanya writing center di universitas sudah banyak diteliti. Perbandingan antara mahasiswa yang menggunakan dan tidak menggunakan jasa writing center menunjukkan keunggulan dan manfaat tertentu. Peningkatan kepercayaan diri, self-efficacy, dan persepsi yang lebih baik terhadap kemampuan diri sendiri setelah mengikuti proses tutoring di writing center adalah salah satu pengaruh terpenting dari partisipasi mahasiswa dalam writing center (Bielinska-Kwapisz, 2015). Dampak positif dari writing center tidak hanya dapat dirasakan dari pengguna tetapi juga berdampak kepada tutor atau peer consultant yang memberikan sesi konsultasi penulisan, secara akademis dalam kompetensi penulisan ilmiah maupun untuk aspek soft skills dan pengembangan diri (Nainggolan et al., 2013). Adanya hubungan yang baik antar peer consultant dan pengguna writing center dapat membuat pengguna atau penulis ilmiah merasakan kecemasannya yang menurun karena 
dapat membagian rasa kesulitannya dan merasa memiliki tujuan yang sama dengan konsultan dalam writing center (Rohan, 2020).

Keberadaan writing center menunjukkan praktik kemampuan bekerja sama antara pengguna dan PC. Arti teamwork berasal dari 2 asal kata, yaitu team dan work. Team adalah sebuah grup yang berkolaborasi dalam pekerjaan profesional atau dalam beberapa penugasan perusahaan. Work adalah tindakan yang melibatkan suatu upaya atau usaha pada tujuan yang pasti. Berdasarkan arti tersebut, teamwork atau kemampuan bekerja sama dapat diartikan sebagai pekerjaan yang dapat diselesaikan oleh orang yang bekerja sebagai sebuah tim atau kelompok dengan upaya dan usaha bersama (Al-Alawneh, 2011). Definisi keterampilan bekerja dalam tim adalah keterampilan yang membantu pekerjaan individu dan sebagai bentuk kolaborasi yang efektif sebagai anggota dari tim tertentu. Kerja sama menjadi salah satu konsep yang sering digunakan untuk manajemen sumber daya manusia dan sebagai pemanfaatan keahlian dan keterampilan tenaga kerja (Gapinski, 2018).

Elemen yang harus ada agar seseorang dapat meningkatkan kemampuan bekerja sama dalam tim adalah positive interdependence, promotive interaction, individual accountability dan tanggung jawab personal, kemampuan sosial, dan berproses dalam kelompok. Positive interdependence adalah usaha suatu tim untuk mencapai hasil yang sukses dengan kemampuan bersama. Promotive interaction dapat dilakukan jika suatu tim sudah memiliki rasa saling tergantung sehingga dapat memberikan dukungan dan semangat antar tim. Walaupun rasa saling terikat antar anggota tim diperlukan, tanggung jawab personal dan akuntabilitas diri merupakan faktor yang penting agar umpan balik yang diberikan antar anggota tim bisa membangun usaha yang lebih maksimal untuk mencapai tujuan tim (Gapinski, 2018).

Kemampuan untuk saling memimpin dalam tim serta pemantauan kinerja tiap anggota juga diperlukan. Kemampuan memimpin dapat digunakan sebagai koordinasi pembagian tugas di dalam kelompok dan pembuatan rencana tugas tetapi perkembangan masing-masing personal anggota tim diperlukan untuk membentuk kondisi dan lingkungan kerja yang positif. Pemantauan kinerja diperlukan untuk membentuk lingkungan yang suportif dan saling memahami tugas antar anggota sehingga dalam kondisi mendesak dapat dilakukan redistribusi beban kerja atau perilaku backup (Morris et al., 2017).

Kolaborasi dan kemampuan bekerja sama dalam satu kelompok adalah satu hal yang dapat membuat tim bisa bertahan untuk mencapai tujuan yang sama. Kolaborasi dan kerja sama dapat menjamin produktivitas masing-masing orang meningkat. Menurut Gapinski (2018), pembelajaran dengan kolaborasi dapat membuat pendekatan edukasi yang lebih baik dengan membuat mahasiswa bekerja sama untuk mencapai tujuan pembelajaran dengan bimbingan konsultan atau instruktur. Penulisan karya ilmiah juga merupakan kerja kolaboratif terutama di lingkungan pekerjaan (Deveci, 2018).

Kemampuan berpikir secara kritis dan kemampuan bekerja sama akan meningkat dengan adanya penulisan kolaborasi. Penulisan kolaborasi juga dapat membentuk suatu inovasi baru dan penyelesaian konflik yang lebih baik (Deveci, 2018). Pembelajaran kolaborasi juga dapat memberikan manfaat secara langsung terhadap capaian akademik, kemampuan berpikir kritis, komunikasi, dan manajemen diri yang lebih baik (Chandra, 2015).

Selain dalam penulisan ilmiah, kemampuan bekerja sama dianggap sebagai komponen esensial untuk dapat melakukan kolaborasi interprofesional dan interdisiplin dalam sebuah tim (Weller, 2014). Keterampilan kerja sama dalam tim yang baik dapat meningkatkan proses kerja dan hasil secara interprofesi, khususnya mengenai kesadaran tentang pelayanan kesehatan dan perawatan pasien di bidang medis (Morris, 2017). Kerja sama yang dilakukan interprofesi harus memiliki beberapa elemen inti, yaitu memegang identitas tim yang sama sehingga ada rasa saling bergantung, berintegrasi dan tanggung jawab bersama. Tugas dan tipe kerja yang dilakukan pada kerja sama interprofesi biasanya mendesak dan bersifat kompleks sehingga hasil yang lebih 
efektif dapat dicapai jika setiap anggota tim memiliki kemampuan bekerja yang baik (Gapinski, 2018).

\section{METODE PENELITIAN}

Penelitian ini menggunakan metode campuran studi deskriptif dan eksploratif secara potong lintang. Studi deskriptif dilakukan secara kuantitatif pada tiga titik pengambilan data menggunakan Teamwork Skills Questionnaire (Brungart, 2009). Studi eksploratif menggunakan wawancara mendalam pada subyek yang dianggap dapat memberikan informasi dan pandangan yang luas dengan komunikasi yang baik. Program Atma Jaya Writing Center (AJWC) telah dijalankan dengan nama AtmaLib Writing Resource and Support (AWRS). Data kuantitatif diambil pada seluruh peserta AJWC berjumlah 24 orang, yaitu 10 orang peer consultant (PC) dan 14 orang pengguna. Wawancara dilakukan pada 12 subyek, 6 PC dan 6 pengguna.

Dalam penelitian kuantitatif, hasil dan analisis penelitan perlu diperhatikan. Metode penelitian kuantitatif perlu menjamin pengukuran validitas dan reliabilitas. Validitas diartikan sebagai keakuratan sebuah variabel penelitian dan reliabilitas diartikan sebagai keakuratan pengukuran dari instrumen penelitian sehingga dapat memberikan hasil yang konsisten pada situasi penelitian yang sama (Heale \& Twycross, 2015).

Pengukuran kemampuan bekerja sama dalam tim paling baik dilakukan saat proses bekerja dalam tim namun sering kali tidak memungkinkan pada beberapa kasus dan kondisi. Teamwork skills questionnaire dibuat dan digunakan untuk mengukur keterampilan bekerja sama dalam tim secara tidak langsung. Pengukuran menggunakan kuesioner ini dapat dilakukan pada individu yang sedang atau tidak berpartisipasi dalam kerja tim. Pengukuran dalam kuesioner ini terdiri dari enam keterampilan kerja yang menilai efektivitas kerja seseorang sebagai bagian dari sebuah tim, yaitu koordinasi untuk mengatur rancangan kerja agar selesai tepat waktu, pengambilan keputusan, kepemimpinan, interaksi interpersonal antar anggota tim, kemampuan beradaptasi dalam mengenali dan mengatasi masalah, dan komunikasi yang efektif untuk bertukar informasi secara jelas dan akurat. Hasil dari pengukuran kuesioner ini merupakan persepsi partisipan mengenai keahlian masingmasing pribadi dari setiap keterampilannya (Brungardt, 2009 \& Gapinski, 2018).

Content analysis atau analisis isi adalah salah satu metode penelitian yang paling sering digunakan untuk mengembangkan hasil dari

penelitian kualitatif. Content analysis mencakup analisis perilaku dan bahasa yang muncul sebagai hasil penelitian. Analisis isi dilakukan untuk memahami secara komprehensif pesan atau kata yang didapat dari hasil penelitian tetapi hanya untuk definisi tertentu (Neuendorf, 2017).

Metode analisis isi data kualitatif yang paling sering digunakan adalah metode analisis wacana. Analisis wacana adalah mengkaji hasil penelitian yang terdapat pada pesan komunikasi publik, baik secara bahasa maupun gerakan kontekstual (Neuendorf, 2017). Analisis wacana biasa didapatkan berupa penjelasan pada kata tanya "bagaimana" dan "mengapa". Pada penjelasan Ahmad (2018), analisis wacana mementingkan pemaknaan suatu bahasa daripada data kuantitatif lainnya yang disampaikan. Hasil analisis isi wacana tidak dapat digeneralisasi karena setiap penyampaian memiliki makna yang berbeda dan berfokus pada penggunaan bahasa tertentu. Analisis percakapan juga dapat digunakan untuk menganalisis komunikasi yang terjadi secara alami.

Informasi dan interpretasi dalam analsisis isi sifatnya beragam sehingga analisis memiliki ketelitian yang lebih baik saat transkripsi data maupun analisis transkripsi (Renz, 2018). Analisis isi sebagai bagian dari riset kualitatif perlu menjamin transferability dan dependability. Transferability memberikan kemungkinan terluas agar data dan hasil analisis dapat dipahami segenap pihak. Dependability memberikan jaminan agar data, analisis data, dan interpretasi riset kualitatif dapat diandalkan (Cresswell, 2017). Oleh karena itu, kedua prinsip tersebut dapat dijamin dengan triangulasi data, inter-rater agreement dan audit 
trial. Dalam penelitian ini triangulasi data diambil dengan metode kuantitatif melalui Teamwork Skills Questionnaire dan melalui wawancara mendalam dengan subyek PC dan pengguna. Inter-rater agreement dilakukan melalui analisis isi oleh tiga orang berbeda (satu orang di luar tim peneliti) secara terpisah dan dilakukan pertemuan antar inter-rater untuk membahas analisis isi yang belum disepakati. Inter-rater agreement meningkat dari 17,8\% menjadi $95,5 \%$ setelah pertemuan. Dalam melakukan proses rater, peneliti menggunakan QDA Miner Lite untuk membantu mengolah data kualitatif. Sementara itu, audit trail dilakukan oleh seorang periset kualitatif yang berpengalaman dan tidak terlibat dalam penelitian ini. External auditor dengan demikian melihat kesinambungan antara tujuan penelitian, metode riset, analisis data, dan hasil interpretasi data. Hasilnya, auditor menyatakan konsistensi penelitian ini unggul.

\section{HASILDAN PEMBAHASAN}

Hasil pengukuran menggunakan Teamrwork Skills Questionnaire ditampilkan dalam grafik dan tabel. Keemampuan bekerja sama dihitung dari item koordinasi, pembuatan keputusan, kepemimpinan, kemampuan interpersonal, adaptabilitas dan komunikasi dari hasil pengukuran yang diambil dari tiga titik pengambilan data. Pada gambar 1, ditunjukkan data pada tiga titik pengambilan pada $\mathrm{PC}$ dengan hasil yang sama pada ketiga titik, yaitu $80 \%$ pada kategori tinggi dan $20 \%$ pada kategori sedang. Data pada gambar 1, dilakukan uji analisis ANOVA Repeated Measures dan didapatkan perbandingan data ketiga titik seperti pada tabel 1 tidak ditemukan perbedaan yang bermakna antara ketiga titik pengambilan data untuk PC.

Hasil pengukuran terhadap pengguna AJWC, didapatkan data yang berbeda pada titik ketiga seperti yang digambarkan pada gambar 2 . Pengguna jasa AJWC menunjukkan kemampuan kerja sama kategori tinggi yang meningkat dari 50\% menjadi 64\%. Peningkatan data tersebut, didapatkan adanya perbedaan bermakna saat dilakukan perbandingan data menggunakan ANOVA Repeated Measures antara titik pertama dan kedua dibandingkan dengan titik ketiga seperti yang ditunjukkan pada tabel 2 .

Data kualitatif diperoleh melalui wawancara melalui telepon via Microsoft Teams pada bulan November - Desember 2020. Wawancara dilakukan terhadap 12 responden, terdiri dari 6 responden peer consultant dan 6 responden pengguna, yang telah mengisi kuesioner dan sesuai dengan kriteria inklusi. Seluruh wawancara yang dilakukan direkam dengan persetujuan partisipan dan memiliki waktu 24-40 menit per wawancara. Tabel kategori atau coding table dibuat oleh peneliti sesuai dengan tema yang muncul dari hasil wawancara. Analisis konten (content analysis) dilakukan oleh tiga inter-rater berdasarkan tabel kategori. Pada hasil akhir agreement, didapatkan total terdapat 15 kategori dengan 27 kode.

PC menyadari aspek kerja sama yang penting adalah komunikasi. Beberapa kutipan dibawah memberikan pernyataan PC bahwa dalam program writing center aspek kerja sama secara keseluruhan dirasakan kurang mendalam karena hubungan PC hanya dua arah dengan penggunanya, meskipun demikian PC merasakan aspek komunikasi berkembang pesat.

"Sebenernya sih agak kurang karena hanya dijalankan bersama oleh 2 orang. Maksudnya 1 ketemu 1 untuk konsul KTI nya, secara overall agak kurang kerja sama. TAPI untuk melatih komunikasi bisa sih. Mungkin kalau mengambil keputusan dan sebagainya, terus membantu anggota lain, maksudnya karena hanya berdua tanpa ketua dan anggota kan, jadi kerjsama kurang bisa diliat disitu. Tapi kalau diliat dari komunikasi, gimana cara mendengarkan, kalau misalnya kemarin ada yang konsul KTI dan ternyata dia ada kesulitan, masalahnya karena apa, ternyata itu sambil ngebantu dia menyelesaikan masalah dia diluar KTInya, dan berefek untuk membantu KTInya biar cepet beres, bisa melatih komunikasi. Kan kerja sama salah satu poin pentingnya adalah 
komunikasi, yah jadi sedikit banyak bisa memengaruhi kerja sama. Tapi kan ngga gitu banyak sih." (PC 1)

"Kalau koordinasi sih, aku yang penting saling ngabarin. Jadi kayak misalnya kerja sama ehm dengan apa ya.. tugas yang bedabeda gitu. Nah, masing-masing orang itu ngabarin kayak "gw tugasnya ini", "sekarang gw udah ngecapai ini, lu gimana?". Jadi, koordinasi yang baik, harus ada komunikasi kali. "(Pengguna 5)

Dalam peran sebagai leader, PC mencatat pentingnya seorang pemimpin mengambil kepurusan dan memberikan arah kepada anggotanya dalam peran sebagai leader. PC merefleksikan perannya sebagai leader. Sementara pada aspek pertumbuhan, PC memandang pengalamannya menjadi peerconsultant dengan penugasan yang diberikan oleh AJWC menumbuhkan pengalaman bermakna.

"Maksudnya, pertama mesti disepakati dulu figur ketua penting gitu. Jadi kalau misalnya semua orang punya pendapat, mau pendapat mana yang dipakai. Termasuk juga kalau pendapatnya semuanya jelek, hm ya ketua juga mesti bilang ini belum bagus kita mesti cari lagi ide-ide lainnya. Kalau misalnya ketuanya punya ide "kalau gini gimana?" abis itu dijelasin kenapa ini bagus dan sebagainya. Kalau yang lain terima-terima aja, ya udah akhirnya diambil." (PC 1)

"Lama-lama kan orang yang kurang ini karena banyak diajarkan dan banyak belajar juga dari pengalamannya dia untuk bekerja itu, nanti lama-lama bisa, tadi kan awalnya dia dikasih tugas yang ngga krusial dulu, lama -lama naik level gitu, dikasih tugas yang krusial gitu. "(PC 6)

Manajemen AJWC mensyaratkan tenggat waktu dalam berkarya sebagai PC. Dengan cara ini, PC mempunyai manajemen waktu dan problem yang baik. Inisiatif menyelesaikan tugas sebelum tenggat waktu juga merupakan latihan yang baik bagi PC dan pengguna AJWC.

"Sebenernya ya penting lah ada deadline. Kalau ngga ada deadline, semua manusia punya tendency untuk procrastinate gitu. Kalau ngga ada deadline, hasilnya ngga akan pernah jadi. Mundurin aja terus mundur, gitu." (PC 6)

"Oh nanya tugas mereka udah sampe mana, udah sampe mana gitu ya. Hm sebenernya gw jarang ngerjain kayak gitu sih. Jadi gw mau ngelakuin itu kalau misalkan deadline-nya udah mepettt banget baru gw cariin, oh yang ini belum ada, baru gw tanya-tanya ini udah kelar apa belum, kenapa belum dimasukin. Cuma kalau dari awal nge-track engga banget sih. Gw biasanya kerjain punya gw dulu baru kalau udah H-2, H-1, baru ditanya ke orang-orang gitu kalau yang belum selesai." (PC 5)

Pendapat mengenai kesetaraan dalam AJWC merupakan temuan penting yang menunjukkan atmosfer belajar yang sangat mendukung karena adnya kesetaraan.

"Setara itu hal yang paling tidak ditemukan sih dalam bekerja yang sama-sama gitu. Mungkin dari jabatannya sama-sama anggota itu setara kali ya. Itu kesetaraan yang bisa dikasih gitu. Kalau misalnya mau ngevote atau apa ya semua orang punya hak untuk memberi suara, ya mungkin itu setara. Kalau misalnya ya bagi tugas, berpendapat, semua orang setara. Cuman treatmentnya sih setara mungkin, tapi ngga bisa sih, ngga bisa setara. Treatment bisanya mesti beda-beda karena setiap orang beda-beda." (PC 1)

Hasil analisis dampak AJWC dapat dilihat dalam peta konsep pada Gambar 3. Tujuan penelitian ini untuk memahami aspek kerja sama dalam tim antara PC dan pengguna AJWC. Melalui data kuantitatif dan kualitatif ditemukan enam kategori utama dalam 
kemampuan kerja sama seperti pada Brugardt (2009). Komponen dalam Teamwork Skills Questionnaire dibagi menjadi enam, yaitu koordinasi, pembuatan keputusan, kepemimpinan, kemampuan interpersonal, adaptabilitas dan komunikasi. Masing-masing komponen yang terdapat pada kerja sama ditinjau dari beberapa hal yang didapatkan selama penelitian, seperti tujuan dan perencanaan, jobdesc atau pembagian tugas, role model pada leader hingga komunikasi yang dijalankan dengan diskusi yang terbuka. Gambaran mengenai komponen kerja sama dapat dinilai pada pengambilan data kualitatif yang menggambarkan bagaimana proses kerja sama yang dilakukan oleh para responden di AJWC.

Hasil yang didapatkan pada ketiga titik pengambilan data pada peer consultant menunjukkan tidak ada perbedaan bermakna pada persentase kategori kemampuan kerja sama peer consultant (tinggi 80\% dan sedang $20 \%$ ). Hal ini menunjukkan tidak ada pengaruh AJWC pada kemampuan kerja sama peer consultant. Tidak adanya perbedaan peningkatan pada ketiga titik penelitian $(p=0,857)$ juga dapat terjadi karena masingmasing PC sudah memiliki kemampuan kerja sama yang tinggi dari awal dilakukannya penelitian ini atau sebelum mengikuti AJWC. Hal ini menjadi suatu keunggulan yang diapatkan dalam penelitian ini karena PC AJWC yang direkrut adalah mahasiswa yang memiliki kemampuan kerja sama baik dan dapat menyampaikan bimbingan kepada penggunanya dengan interaksi yang membantu pengguna.

Analisis data kualitatif yang didapatkan dari wawancara terhadap PC menunjukkan AJWC tidak berpengaruh secara langsung kepada kemampuan kerja sama namun setelah digali lebih lanjut, PC menyatakan bahwa AJWC memiliki pengaruh pada komponen kerja sama dalam pribadi PC, seperti meningkatkan kemampuan komunikasi dengan orang lain dan meningkatkan kemampuan beradaptasi dalam lingkungan baru dan orangorang yang baru. Hal ini mirip dengan penelitian sebelumnya saat peer-tutor sungguh merasa dapat lebih berkembang dari segi komunikasi, presentasi kepada orang lain dan memiliki pengetahuan yang lebih luas saat berdiskusi dengan penggunanya dalam sesi peer-tutoring secara akademik. (AlShareef et al., 2019)

Peta konsep menjelaskan komponen kerja sama yang dirasakan oleh pada pengguna dan PC AJWC. Sebagai bentuk kerja sama, responden menyatakan bahwa kondisi kerja sama dapat terjadi jika terdapat lebih dari dua orang yang memiliki tujuan yang sama sedangkan terdapat responden lain yang menyatakan bahwa kerja sama tetap bisa berjalan walau masing-masing anggota memiliki tujuan yang berbeda tetapi memiliki sikap yang kooperatif. Kerja sama yang baik yang dialami oleh responden dipengaruhi oleh koordinasi dan komunikasi yang berjalan lancar. Hal ini ditemukan dari hasil wawancara bahwa setiap kerja sama tim diperlukan koordinasi yang baik di awal kesepakatan kelompok. Koordinasi untuk menyamakan persepsi dan membuat perencanaan untuk pembagian tugas dan pekerjaan antar anggota dapat meningkatkan kualitas dari kerja sama yang ada. Koordinasi dalam kelompok dapat mencakup pembagian beban kerja yang efektif antar anggota kelompok. Responden menyatakan pembagian tugas yang efektif dan ideal dapat berupa pembagian kerja berdasarkan kemampuan yang dimiliki setiap anggota. Pembagian kerja berdasarkan kemampuan dapat menciptakan hasil maksimal dan memengaruhi kinerja tim. Hal ini ditemukan juga dalam penelitian lain yang menyatakan bahwa adanya ilmu, keterampilan, dan kemampuan menjadi faktor paling utama yang memengaruhi efektivitas kerja tim dan kepuasan anggota. (Hwang, 2018) Dalam koordinasi kelompok, pengambilan keputusan menjadi satu hal yang penting agar pekerjaan dan tugas dibagi dengan tepat. Pembuatan keputusan dapat dilatih pada pengguna saat menentukan pendapat atau saran tertentu yang lebih baik dari PC-nya. Meskipun demikian, pembuatan keputusan kurang berperan dalam tutoring AJWC karena hanya terdapat dua orang 
yang saling berdiskusi saat dilakukannya sesi sehingga pengambilan keputusan tidak dilematis.

Hasil wawancara pada PC menjelaskan bahwa pembuatan keputusan akan dipengaruhi oleh kemampuan memimpin seseorang dalam kelompok. PC menyatakan bahwa leader harus mampu menjadi seorang role model dan menilai, mengelola dan mengoptimalkam kemampuan setiap pribadi anggotanya. PC secara tidak langsung melatih kemampuan memimpin dengan cara memberikan saran dan berusaha untuk memaksimalkan kemampuan pengguna dalam membuat penulisan ilmiah dalam AJWC. Paparan responden mengenai sikap interpersonal dalam berkelompok adalah dengan cara berbicara secara terbuka dan menghargai setiap pendapat anggotanya saat menghadapi situasi konflik yang memengaruhi kinerja tim. Penelitian Driskell (2018) menytakan bahwa proses interpersonal adalah salah satu proses penting dalam bekerja sama. PC juga menyatakan bahwa selama menjalani program AJWC, PC dituntut untuk beradaptasi terhadap perbedaan kepribadian para pengguna dalam layanannya. Responden juga menyatakan bahwa kepribadian yang berbeda dapat menjadi hal yang positif dengan mengembangkan sudut pandang baru pada masing-masing pribadi. Perbedaan kepribadian juga memengaruhi interaksi antar anggota dalam kelompok. Hal ini juga yang akan memengaruhi dasar komunikasi sehingga bisa berjalan efektif secara dua arah oleh anggota kelompok.

Responden menyatakan dalam wawancara bahwa selain enam komponen yang terdapat dalam instrumen penelitian, lingkungan yang nyaman dapat membuat kinerja anggota kelompok lebih baik dan kerja sama tim lebih efisien. Hal ini juga dijabarkan dalam penelitian terdahulu yang menyatakan bahwa salah satu faktor yang memengaruhi kinerja tim adalah kepuasan anggota terhadap kelompoknya, termasuk di dalamnya lingkungan yang nyaman dan kontribusi anggota lainnya dalam bekerja bersama. (Hwang, 2018)

Hasil penelitian yang didapatkan pada data pengguna menunjukkan bahwa ada perbedaan signfikan pada kemampuan kerja sama yang dirasakan pada pengguna $(\mathrm{p}=0,044)$. Perbedaan ini terlihat jelas dari rerata data penelitian dari titik pertama hingga titik ketiga. Selain itu, perbedaan juga sangat terlihat dari masingmasing data di titik pengambilan bahwa data ketiga menunjukkan terdapat peningkatan pada responden yang memiliki kategori kerja sama yang tinggi (data pertama dan kedua 50\% sedangkan data ketiga 63,4\%). Dalam temuan peer mentoring yang dilakukan oleh Andersen (2018), terlihat bahwa pengguna atau mentee yang dibantu dalam proses mentoring atau tutoring merasakan bahwa mereka dapat memelajari cara kooperasi dan kolaborasi yang menjadi salah satu poin penting di dalam kerja sama. Penelitian serupa juga menunjukkan bahwa dengan tutor sebaya dapat meningkatkan kemampuan komunikasi pada tutor maupun penggunanya (Khalid, 2018).

Manfaat lain dari AJWC di luar kemampuan bekerja sama juga didapatkan oleh para pengguna, yaitu membantu penulisan karya tulis para pengguna dan memberikan ide baru ataupun saran untuk penulisannya agar cepat selesai. Dalam wawancara, responden menyatakan bahwa program AJWC dapat membantu mereka dalam penulisan karya tulis ataupun skripsi melalui saran dari tutor sebaya. Penelitian yang dilakukan oleh Khalid menunjukkan bahwa tutor sebaya yang dilakukan pada mahasiswa kedokteran paling efektif sebagai pembelajaran karena dapat membuat atmosfer belajar yang lebih personal pada mahasiswa sehingga mahasiswa lebih percaya diri (Khalid, 2018).

Data penelitian ini mengungkap bahwa AJWC secara signifikan dapat meningkatkan kemampuan kerja sama pada pengguna. Hasil wawancara juga menunjukkan bahwa pengguna merasa terbantu dengan adanya program AJWC untuk menyelesaikan penulisan ilmiah. Selain dari segi pengguna, $\mathrm{PC}$ juga merasa AWJC dapat membantu mengembangkan soft skills, seperti komunikasi dan adaptabilitas.

Writing center perlu diterapkan dan dilanjutkan sebagai program yang selalu tersedia oleh perpustakaan di setiap fakultas dan universitas bagi mahasiswanya sehingga dapat membantu penulisan dan publikasi ilmiah 
sebagai respons temuan positif dalam penelitian ini. Program writing center juga dapat dilanjutkan agar bisa membantu meningkatkan soft skills kerja sama yang secara nyata dapat dilatih dalam tim antara PC dan pengguna program writing center.

\section{E. KESIMPULAN}

Penelitian ini telah menunjukkan bahwa peer-consultant dan pengguna AJWC memiliki tingkat kerja sama yang tinggi, baik sebelum dilakukan program AJWC hingga terselesaikannya program AJWC. Peerconsultant AJWC tidak mengalami perbedaan skor kemampuan kerja sama yang bermakna sedangkan pengguna AJWC memiliki peningkatan kemampuan kerja sama yang signifikan yang membuktikan bahwa program AJWC berpengaruh dalam tingkat kerja sama pada penggunanya. Penelitian juga menggambarkan bahwa setiap responden memiliki gambaran kerja sama yang cukup baik jika dinilai dari masing-masing komponen yang mencakup proses terjadinya kerja sama dalam kelompok. Hal ini ditunjukkan dari penjelasan mendalam mengenai komponen kerja sama dari hasil wawancara. Hal-hal terkait komponen penting dalam kerja sama telah dijelaskan dalam pernyataan wawancara oleh responden.

Peningkatan kemampuan kerja sama yang bermakna melalui kerja sama antara pengguna jasa writing center dengan peer-consultant memberikan peluang menjanjikan dari peranan writing center di perguruan tinggi. Aktivitas dalam writing center tidak hanya membantu peningkatan kemampuan menulis mahasiswa namun secara langsung juga membangun kerja sama antar pihak. Hal ini dapat menjadi awal yang baik bagi perguruan tinggi untuk membangun kapasitas mahasiswanya. Implementasi writing center di perguruan tinggi dapat pula didampingi dengan penelitian dampak terhadap produk ilmiah mahasiswa dari segi kuantitatif maunpun kualitatif. Penelitian lanjutan mengenai manajemen writing center dalam unit kerja yang tepat di perguruan tinggi dapat menumbuhkan standar mutu writing center di perguruan tinggi Indonesia.

\section{DAFTAR PUSTAKA}

Ahmad, J. (2018) Desain penelitian analisis isi (content analysis). Jurnal Sekolah Pascasarjana UIN Syarif Hidayatullah. https://www.researchgate.net/profile/ Jumal-Ahmad/publication/325965331 Desain Penelitian Analisis Isi Content Analysis/links/5b305090a6fdec8506cb8b $\overline{2}$ 1/Desain-Penelitian-Analisis-Isi-ContentAnalysis.pdf

Al-Alawneh, M. K., Meqdadi, R., Al-Refai, A., Khdair, R., \& Malkawi, A. (2011). Examining the effect of college type, study level, and gender of students on their use of teamwork skills as they perceived. Yarmouk University of Jordan, Canadian Social Science, 7(6), 48-57. http://flrjournal.org/index.php/css/article/view/j.cs s.1923669720110706.282

Andersen, T., \& Watkins, K. (2018). The value of peer mentorship as an educational strategy in nursing. Journal of Nursing Education, 57(4),217-224. http://dx.doi.org/10.3928/0148483420180322-05

Chandra, R. (2015). Collaborative learning for educational achievement. 2015. OSR Journal of Research \& Method in Education. IOSR-JRME, 5(02). h t t p : / / i os rjournals.org/ios r jrme/papers/Vol-5\%20Issue-3/Version1/B05310407.pdf

Creswell, J. W., \& Plano Clark, V. L. (2017). Designing and conducting mixed methods research (3rd ed.). SAGE Publications. https://doi.org/10.1177/193758671983222 3

Dansereau, D., Carmichael, L.E., \& Hotson, B. (2020) Building first-year science writing skills with an embedded writing instruction program. Journal of College Science Teaching 49,66-75. https:// search.proquest.com/docview/233075990 7/fulltextPDF/93B2AE1062C94379PQ/1? accountid $=48149$

Deveci, T. (2018). Student perceptions on collaborative writing in a project-based course. Ujer, 6(4),721-32. https://eric.ed.gov/?id=EJ1175391 
Driskell, J.E., Salas, E., \& Driskell, T. (2018) Foundations of teamwork and collaboration. The American psychologist, 73(4), 334-348. https://doi.org/ 10.1037/amp0000241Bielinska-Kwapisz, A. (2015). Impact of writing proficiency and writing center participation on academic performance. The International Journal of Educational Management, 29(4),382-394. http://dx.doi.org/ 10.1108/IJEM-05-2014-0067

Fry, S.W., Keith, M., Gardner, J., Gilbert, A.B., Carmona, A., Schroeder, S., \& Kleinsasser, A. (2019). Entering a community of writers: The writing center, doctoral students, and going public with scholarly writing. The Qualitative Report, 24(11),2832-2850. https://search.proquest.com/scholarlyjournals/entering-community-writerswriting-center/docview/2322631589/se2? accountid $=48149$

Gapinski, A.J. (2018). Assessment of effectiveness of teamwork skills learning in collaborative learning. Journal of Management \& Engineering Integration, 11(2),1-15. https://search.proquest. com/scholarly-journals/assessmenteffectiveness-teamwork-skills learning/docview/2316725041/se2 ? accountid $=48149$

Heale, R., \& Twycross, A. (2015). Validity and reliability in quantitative studies. Evidence - Based Nursing, 18(3),66. http://dx.doi.org/10.1136/eb-2015-102129

Hwang, M.I. (2018). Relationship between teamwork and team performance: Experiences from an ERPsim Competition. Journal of Information Systems Education, 29,157-167. https://www.proquest.com/ scholarly-journals/relationship-betweenteamwork-team-performance/docview/ $2112124524 /$ se-2? accountid $=201395$

Kementrian riset dan teknologi republik Indonesia. Pedoman Publikasi Ilmiah 2017. http://p4.mercubuana.ac.id/wpcontent/uploads/2019/07/PedomanPublikasi-Ilmiah.pdf.
Kementrian Riset dan Teknologi Republik Indonesia. Pedoman tata kelola jurnal menuju bereputasi tinggi 2017. http://lppm.ut.ac.id/system/files/artikel/do kumen/files/Final\%20Pedoman\%20Publik asi_20Juli2017.pdf.

Khalid, H., Shahid, S., Punjabi, N., \& Sahdev, N. (2018). An integrated 2-year clinical skills peer tutoring scheme in a UK-based medical school: perceptions of tutees and peer tutors. Advances in Medical Education and Practice, 9, 423-432. http://dx.doi.org/10.2147/AMEP.S159502

Mackiewicz, J., \& Thompson, I. (2013). Motivational scaffolding, politeness, and writing center tutoring. The Writing Center Journal. 33(21),38-73. https://www.jstor. org/stable/43442403

McGurr, M.J. (2020). Writing centers, libraries, and medical and pharmacy schools. Journal of the Medical Library Association, 108(1),84-88. http://dx.doi.org/10.5195/ jmla.2020.714

Morris, G., Fell, C.W.R., Box H., Farrell, M., \& Stewart, A. (2017). Learning health 'safety' within non-technical skills interprofessional simulation education: a qualitative study. Medical Education Online; Abingdon, 22(1). http://dx.doi.org/10.1080/10872981.2017. 1272838

Nainggolan, A.M., Rukmini, E., \&Ali, S. (2013) Writing center dan Implikasinya terhadap pengguna dan peer consultants di Unika Atma Jaya. Thesis. Unika Atma Jaya Jakarta. https://lib.atmajaya.ac.id/ Uploads/Fulltext/206308/KTI_AL\%20M ARTIN\%20N_2013060098.pdf

Neuendorf, K.A. (2017). The Content Analysis Guidebook. ( $2^{\text {nd }}$ edition). California. https://methods.sagepub.com/book/thecontent-analysis-guidebook-2e.

Prayag, A. (2019). Overview and principles of scientific writing. Indian Journal of Medical and Paediatric Oncology, 40(3),420-423. http://dx.doi.org/10.4103/ ijmpo.ijmpo_131_19 
Renz, S.M., Carrington, J.M., \& Badger, T.A. (2018). Two strategies for qualitative content analysis: An Intramethod Approach to Triangulation. Journal of Healthcare Quality Research, 28(5),824-831. https://doi.org/10.1177/104973231775358 6

Rohan, A., \& Fullerton, J. (2020). Interdisciplinary peer mentorship: An innovative strategy to enhance writing competency. Journal of Nursing Education, 59(3), 173-175. http://dx.doi.org/ 10.3928/01484834-20200220-11

Saad, M. A., Abdulrahman, Y. A., Hamid, M. A., Alosaimi, M. B., Muteb, M. A., Abdulaziz, A. A., \& Hamad, A. A. (2019). Perceptions on reciprocal peer teaching among medical students as learners and as tutors. Advances in Medical Education and Practice, 10, 817-827. http://dx.doi.org/10.2147/ AMEP.S220728
Simkin, M.G., Crews, J.M., \& Groves, M.J. (2012). Student perceptions of their writing skills: Myth and reality. Journal of Business and Management. 18(1),81-95. https://search.proquest.com/docview/1439 527486/fulltextPDF/862532C3C4674375 $\mathrm{PQ} / 1$ ? accountid $=48149$

SINTA - Science and Technology Index. (2020). Ristekbrin.go.id. https://sinta.ristekbrin. go.id/ 


\section{DAFTAR GAMBAR}

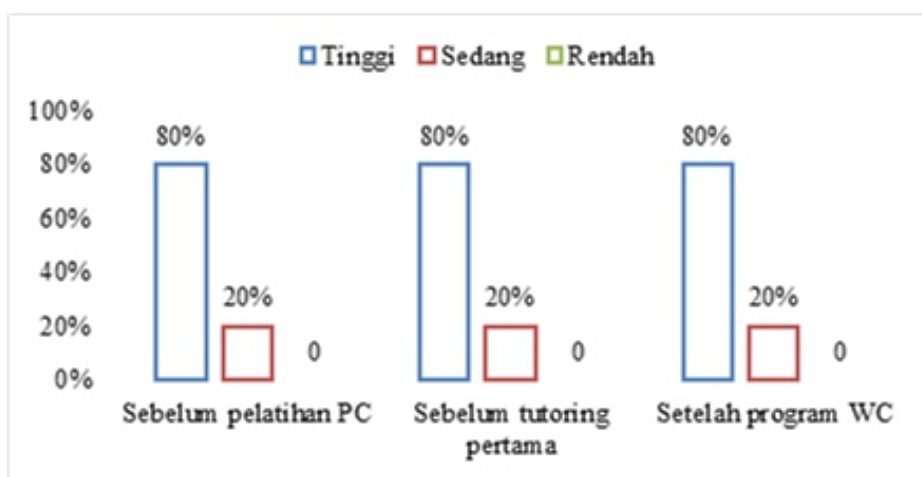

Gambar 1. Data Tiga Titik Teamwork Skills Questionnaire pada PC Sumber: Data primer diolah tahun 2021

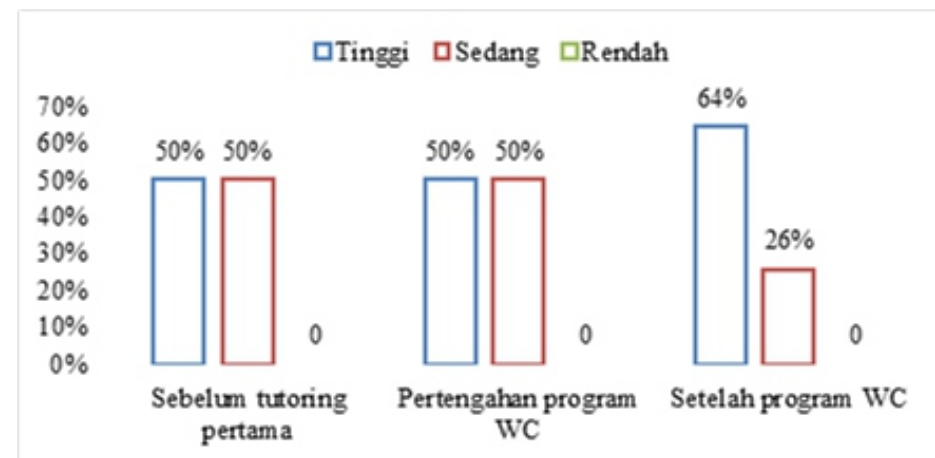

Gambar 2. Data Tiga Titik Teamwork Skills Questionnaire pada Pengguna Sumber: Data primer diolah tahun 2021

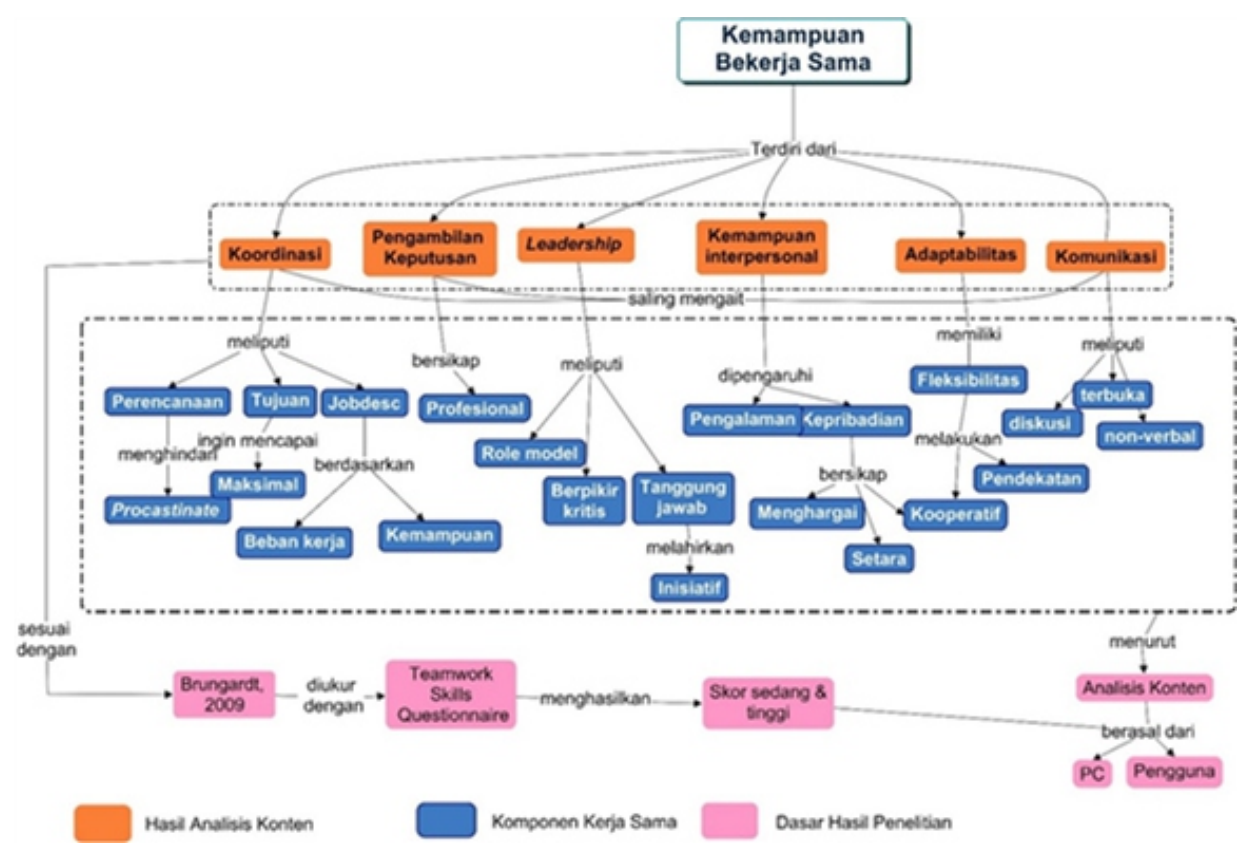

Gambar 3. Peta Konsep Analisis Dampak AJWC terhadap PC dan Penggunanya Merupakan Hasil Analisis dan Interpretasi Data Kualitatif 


\section{DAFTAR TABEL}

Tabel 1. Hasil Uji Perbandingan Data Kuantitatif PC

\begin{tabular}{|c|c|c|c|c|c|c|}
\hline \multirow{2}{*}{\multicolumn{2}{|c|}{ Titik Data }} & \multirow{3}{*}{$\begin{array}{c}\text { Mean } \\
\text { difference }\end{array}$} & \multirow{3}{*}{$\frac{\mathrm{SE}}{4,112}$} & \multirow{3}{*}{$\frac{p}{1,000}$} & \multicolumn{2}{|c|}{ Interval kepercayaan 95\% } \\
\hline & & & & & \multirow{2}{*}{$\begin{array}{c}\text { Lower } \\
-13,861\end{array}$} & \multirow{2}{*}{$\frac{\text { Upper }}{10,261}$} \\
\hline $\begin{array}{c}\text { Sebelum } \\
\text { pelatihan PC }\end{array}$ & $\begin{array}{l}\text { Sebelum tutoring } \\
\text { pertama }\end{array}$ & & & & & \\
\hline & $\begin{array}{c}\text { Setelah program } \\
\text { AJWC }\end{array}$ & $-2,300$ & 3,612 & 1,000 & $-12,895$ & 8,295 \\
\hline \multirow[t]{2}{*}{$\begin{array}{l}\text { Sebelum tutoring } \\
\text { pertama }\end{array}$} & $\begin{array}{c}\text { Sebelum pelatihan } \\
\text { PC }\end{array}$ & 1,800 & 4,112 & 1,000 & $-10,261$ & 13,861 \\
\hline & $\begin{array}{c}\text { Setelah program } \\
\text { AJWC }\end{array}$ & $-0,500$ & 5,158 & 1,000 & $-15,630$ & 14,630 \\
\hline \multirow[t]{2}{*}{$\begin{array}{c}\text { Setelah program } \\
\text { AJWC }\end{array}$} & $\begin{array}{c}\text { Sebelum pelatihan } \\
\text { PC }\end{array}$ & 2,300 & 3,612 & 1,000 & -8.295 & 12,895 \\
\hline & $\begin{array}{l}\text { Sebelum tutoring } \\
\text { pertama }\end{array}$ & 0,500 & 5,158 & 1,000 & $-14,630$ & 15,630 \\
\hline
\end{tabular}

Sumber: Data primer diolah tahun 2021

Tabel 2. Hasil Uji Perbandingan Data Kuantitatif Pengguna

\begin{tabular}{|c|c|c|c|c|c|c|}
\hline \multirow{2}{*}{\multicolumn{2}{|c|}{ Titik Data }} & \multirow{3}{*}{$\begin{array}{c}\text { Mean } \\
\text { difference }\end{array}$} & \multirow{3}{*}{$\frac{\mathrm{SE}}{2,141}$} & \multirow{3}{*}{$\frac{\mathrm{p}}{1,000}$} & \multicolumn{2}{|c|}{ Interval kepercayaan 95\% } \\
\hline & & & & & \multirow{2}{*}{$\begin{array}{l}\text { Lower } \\
-7.665\end{array}$} & \multirow{2}{*}{$\frac{\text { Upper }}{4.094}$} \\
\hline $\begin{array}{l}\text { Sebelum tutoring } \\
\text { pertama }\end{array}$ & $\begin{array}{c}\text { Pertengahan } \\
\text { program AJWC }\end{array}$ & & & & & \\
\hline & $\begin{array}{c}\text { Setelah program } \\
\text { AJWC }\end{array}$ & $-8,000$ & 3,771 & 0.161 & $-18,355$ & 2.355 \\
\hline \multirow[t]{2}{*}{$\begin{array}{c}\text { Pertengahan } \\
\text { program AJWC }\end{array}$} & $\begin{array}{c}\text { Sebelum tutoring } \\
\text { pertama }\end{array}$ & 1,786 & 2,141 & 1,000 & $-4,094$ & 7.665 \\
\hline & $\begin{array}{c}\text { Setelah program } \\
\text { AJWC }\end{array}$ & $-6,214$ & 2,217 & 0.045 & $-12,301$ & -0.127 \\
\hline \multirow[t]{2}{*}{$\begin{array}{c}\text { Setelah program } \\
\text { AJWC }\end{array}$} & $\begin{array}{c}\text { Sebelum tutoring } \\
\text { pertama }\end{array}$ & 8,000 & 3,771 & 1,000 & $-2,355$ & 18.355 \\
\hline & $\begin{array}{c}\text { Pertengahan } \\
\text { program AJWC }\end{array}$ & 6,214 & 2,217 & 0.045 & 0.127 & 12.301 \\
\hline
\end{tabular}

Sumber: Data primer diolah tahun 2021 